\title{
Knowledge and Attitude of Women and Nurses regarding Pre-Conception Care: A Comparative Study
}

\author{
Ekbal Abd El Rheem Emam ${ }^{1}$, Amany Hassan Abd El Rheem ${ }^{2}$ \\ Naglaa Mohammed Amein Ghanem ${ }^{3}$, Hanan Elzeblawy Hassan ${ }^{4 *}$
}

${ }^{1}$ Assistant Professor of Women Health and Obstetric Nursing Department, Faculty of Nursing, Minia University, Egypt

${ }^{2}$ Lecture of woman health and obstetric nursing Department, Faculty of Nursing, Minia University, Egypt

${ }^{3}$ Lecture of community health nursing Department, Faculty of Nursing, Minia University, Egypt

${ }^{4 *}$ Maternal \& Newborn Health Nursing, Faculty of Nursing, Beni-Suef University, Egypt nona_nano_1712@yahoo.com

\section{Abstract}

Background: Despite the established importance of preconception care (PCC), it is still not a well-established service in many countries, and women's and nurses' related knowledge and attitudes need to be assessed.

Aim of the study: To compare the knowledge and attitude of married women and nurses regarding preconception care.

Subjects and methods: This comparative cross-sectional study was carried out on a stratified cluster sample of 106 nurses and 750 women from Maternal and Child Health (MCH) and Primary Health Care (PHC) centers at Minia city. The data collection tools were a self-administered questionnaire measuring nurse's awareness, knowledge, and attitudes related to PCC, and a similar interview questionnaire sheet for women. The tools were validated by experts' opinions and pilot-tested. Data collection lasted from June to November 2017.

Results: The majority of the nurses had a diploma (97.2\%), 72.6\% had training in antenatal care, and $60.4 \%$ provided PCC. Women's age ranged between 17 and 48 years, and 39.5\% had an intermediate education. Nurses' awareness was higher than women ( $\mathrm{p}<0.001)$. They had higher knowledge scores in most areas and in total knowledge $(\mathrm{p}<0.001)$, but women were higher in vaccination $(\mathrm{p}=0.001)$. The attitude towards planning for pregnancy was higher among nurses $(\mathrm{p}<0.001)$. In multivariate analysis nurses' higher qualification, longer experience years, and provision of PCC were positive predictors of their knowledge, while age and urban residence were negative predictors. Higher qualification and provision of PCC were positive predictors of nurses' attitude score, whereas urban residence was a negative predictor. Women's knowledge was positively predicted by their education, previous pre-term labor, planning pregnancy, having antenatal care, having PCC, and previous counseling, while labor complications and chronic diseases were negative predictors. Their attitude was positively predicted by urban residence, planning pregnancy, having antenatal care, previous counseling, and knowledge score, while education was a negative predictor.

Conclusion and recommendations: Nurses' knowledge and awareness of PCC is better compared to women, and both have hesitant attitudes. The study indicates the need for the urgent establishment of a formal PCC in PHC and MCH centers.

Keywords: Knowledge, Attitude, Nurses, Pre-Conception Care 


\section{INTRODUCTION}

Preconception care (PCC) is a service provided to women planning the pregnancy to ensure having a healthy child [1]. In contrast, the antenatal care is provided during pregnancy, but both are integral parts of women reproductive health [2]. The PCC involves health promotive, preventive and curative interventions covering the physical, social, and psychological aspects of woman's life [3-5]. It may also involve genetic counseling and interventions $[6,5]$. The PCC got increasing importance with the World Health Organization Global Action Plan for the Prevention and Control of Non-Communicable Diseases 2013-2020 [7].

There is mounting evidence that PCC could have an essential role in preventing both short and long-term adverse maternal and fetal outcomes of pregnancy [8]. Risk factors for poor outcomes of pregnancy include deficient nutrition with low folic acid intake, obesity, chronic diseases, and unhealthy habits [9-11]. It is anticipated that proper PCC can contribute to reductions in maternal mortality and morbidity worldwide and in particular in developing countries. Examples are the potentials of reducing the risk of neural tube defects through folic acid supplementation three months before conception, as well as the mitigation of the risks associated with smoking, alcohol and other drug consumptions, and occupational hazards [12-16].

Despite the established importance of PCC, it is still not a well-established service in many countries, especially the low-income ones. Moreover, research demonstrated that women's, as well as health care providers' knowledge and practice of PCC, is poor in developing countries [17-20]. This was also demonstrated in developed countries such as the Netherlands [21], although a good PCC program was established in China since 2010 [22]. Knowledge of PCC could be gained by education, training, or experience [23].

\section{SigNifiCANCE OF THE STUDY}

Births resulting from unintended pregnancies are often associated with untoward health outcomes. Hence, the care provided to women should better be before a child is conceived, in order to prevent any birth defects and other adverse outcomes. There are no formal PCC in the local settings, and the related services might be provided during consultations for contraception and follow-up for chronic diseases. Thus, it is expected that the women, as well as the nurses in the study settings, have deficient knowledge and attitudes towards PCC. Moreover, there is a need to investigate the factors affecting such knowledge and attitude in order to set corrective actions.

\section{AIM OF THE STUDY}

The study was conducted to compare the knowledge and attitude of married women and nurses regarding preconception care.

\section{RESEARCH HYPOTHESIS}

It was hypothesized that nurses' scores of knowledge and attitudes will be higher compared to women's scores.

\section{SubJeCtS ANd Methods}

\section{Research Design and Setting}

A comparative cross-sectional design was used in carrying out this study at the Maternal and Child Health $(\mathrm{MCH})$ and Primary Health Care (PHC) centers at Minia city.

\section{Subjects}

The study included two groups of respondents, namely nurses working in the settings and married women attending the settings for vaccination of their infants through the first year of age. Minia city has a total of 19 MCH centers and 309 PHC centers. A stratified cluster sample of these centers was randomly selected. The two 
strata were the MCH and PHC centers, and the centers represented clusters. Then, from each selected center, one or more nurse with at least six-month experience in the service was recruited. The total numbers of nurses were 33 from MCH centers and 73 from PHC centers. Similarly, from each selected center around ten adults married women with at least one previous pregnancy and delivery. Their numbers were 150 from MCH centers and 600 from PHC centers.

The sample size was calculated to demonstrate any difference of statistical significance between nurses and women's knowledge or attitude with a risk ratio 0.75 , expecting a level of $60 \%$ or higher among nurses, at 95\% level of confidence and $80 \%$ study power. Using the Open-Epi software package for the sample size of a difference between two proportions, and setting a sample ratio of nurses to women at 1-to-7, the required sample size after adjusting for a non-response rate of about 5\%, the required samples were 106 nurses and 750 women.

\section{Data collection tools}

The researchers used two different tools for data collection, one for nurses and the other for women.

\section{Nurses' tool}

This consisted of a self-administered questionnaire in Arabic language to assess nurse's awareness, knowledge, and attitudes related to preconception care. It started with a section for personal characteristics as age, marital status, nursing qualification, experience years, residence, training in preconception care, etc. It also included questions about previous personal experience with preconception care and the provision of this service at work.

The second part assessed nurse's awareness of the elements of preconception care. It consisted of 10 elements such as talking with the doctor about pregnancy, medication advice, exercise, etc. The score of total awareness was computed by simple summation of the elements the respondent was aware of. The score was converted into a percent score, and means, standard deviations, and medians were calculated for quantitative statistical analysis.

The third part was intended to assess nurse's knowledge of preconception care. It involved 36 True/False questions covering different aspects of preconception care such as its benefits, services/ elements, risk factors, nutrition, vaccination, as well as chronic and infectious diseases during pregnancy. For scoring, each knowledge item with the correct answer was scored one and the incorrect zero. The scores of the items for each area were summed-up and the total divided by the number of items, giving a mean score for the area. These scores were converted into percent scores, and means, standard deviations, and medians were calculated for quantitative statistical analysis.

The fourth part was an attitude towards pre-conception care. It consisted of 17 positive and negative statements covering areas of pre-conception care as "Preconception care has no impact on pregnancy outcomes," planning for pregnancy such as "Planning for pregnancy is a priority for me," and pre-conception care services such as "PHC centers are the best settings to provide preconception care." The response for each statement is on a 3-point Likert scale from "agree" to "disagree." These were scored from one to three. The scoring was reversed for negative statements so that a higher score indicates more positive attitude. The scores of the statements for each area were summed-up and the total divided by the number of statements, giving a mean score for the area. These scores were converted into percent scores, and means, standard deviations, and medians were calculated for quantitative statistical analysis. 


\section{Women's tool}

This consisted of an interview questionnaire sheet in Arabic language to assess women's awareness, knowledge, and attitudes related to preconception care. It had a section for woman's personal characteristics as age, marital status, education, job, residence, as well as a full obstetric history and previous use of preconception care. The second part was exactly similar to the corresponding part of the nurses' questionnaire, with the same scoring system. The third part assessed women's knowledge of preconception care through 24 True/False questions covering the same areas as in the nurses' form, and the scoring was similar to it. The fourth part was an attitude scale consisting of 12 positive and negative statements covering the same areas of pre-conception care as in the nurses' tool, and it had the same scoring system.

\section{Validity and Reliability of Tools}

The two tools were reviewed by a panel of three experts in women health and obstetric nursing to examine their face and content validity. Modification of the content and rephrasing of some statements were done according to their recommendations. The reliability of the attitude scales was examined through assessing their internal consistency, and they showed a good level of reliability as shown by their Cronbach alpha coefficients.

\section{Pilot Study}

A pilot study was conducted on approximately $10 \%$ of the samples of nurses and women to test the clarity and applicability of the data collection tools, and to determine the time required to fill them. The data collection forms were finalized based on the pilot results.

\section{Ethical Considerations}

The researchers obtained required ethical and administrative approvals to conduct the study. The aim and process of the study were explained to each potential participant nurse and woman, and their oral informed consent was obtained before any data collection. They were informed about their rights to refuse or withdraw from the study at any time. They were reassured about the confidentiality of any obtained information. Professional help was provided to women when needed.

\section{Fieldwork}

Permission to conduct the study was obtained from the directors of $\mathrm{MCH}$ and PHC centers. The researchers first met with the nurses individually and handed the data collection tool to those who gave their consent, along with instructions on how to fill it. It took each nurse approximately 45 minutes to be complete the form. Then, around twelve women were recruited from the center, and they were interviewed using the corresponding form after giving their consent. The woman's privacy was respected during the interview, which took 25-35 minutes. The data collection period lasted for six months from June to November 2017.

\section{Statistical Analysis}

Data entry and statistical analysis were done using SPSS 20.0 statistical software package. Data were presented using descriptive statistics in the form of frequencies and percentages for qualitative variables, and means and standard deviations and medians for quantitative variables. Cronbach alpha coefficient was calculated to assess the reliability of the scales through their internal consistency. Quantitative continuous data were compared using the non-parametric Mann-Whitney test. Qualitative categorical variables were compared using chisquare test. In order to identify the independent predictors of the knowledge and attitude scores, multiple linear regression analysis was used, and analysis of variance for the full regression models done. Statistical significance was considered at $\mathrm{p}$-value $<0.05$. 


\section{RESULTS}

The study sample of nurses included 106 female nurses whose age ranged between 21 and 59 years, mostly diploma degree nurses (97.2\%), with median experience 20 years as illustrated in Table 1. The majorities of these nurses were married (89.6\%), had a previous pregnancy $(80.2 \%)$, and of this $90.6 \%$ had antenatal care. More than two-thirds of them (72.6\%) had attended training in antenatal care, and $60.4 \%$ provided preconception care at their Primary Health Care (PHC) centers.

Table1. Personal characteristics of nurses in the study sample ( $n=106)$

\begin{tabular}{|c|c|c|}
\hline & Frequency & Percent \\
\hline Age: & & \\
\hline$<40$ & 70 & 66.0 \\
\hline $40+$ & 36 & 34.0 \\
\hline Range & \multicolumn{2}{|c|}{$21.0-59.0$} \\
\hline Mean \pm SD & \multicolumn{2}{|c|}{$38.1 \pm 8.6$} \\
\hline Median & \multicolumn{2}{|c|}{37.0} \\
\hline \multicolumn{3}{|l|}{ Marital status: } \\
\hline Single & 11 & 10.4 \\
\hline Married & 95 & 89.6 \\
\hline \multicolumn{3}{|l|}{ Nursing qualification: } \\
\hline Diploma & 103 & 97.2 \\
\hline Bachelor & 3 & 2.8 \\
\hline \multicolumn{3}{|l|}{ Experience years: } \\
\hline$<20$ & 13 & 12.3 \\
\hline $20+$ & 93 & 87.7 \\
\hline Range & \multicolumn{2}{|c|}{$<1.0-40.0$} \\
\hline Mean \pm SD & \multicolumn{2}{|c|}{$18.1 \pm 8.8$} \\
\hline Median & \multicolumn{2}{|c|}{19.0} \\
\hline \multicolumn{3}{|l|}{ Residence: } \\
\hline Rural & 73 & 68.9 \\
\hline Urban & 33 & 31.1 \\
\hline \multicolumn{3}{|l|}{ Had training in: } \\
\hline Pre-conception care & 43 & 40.6 \\
\hline Antenatal care & 77 & 72.6 \\
\hline Had previous pregnancy & 85 & 80.2 \\
\hline Got pre-conception care & 47 & 55.3 \\
\hline Got antenatal care & 77 & 90.6 \\
\hline Provides pre-conception at center & 64 & 60.4 \\
\hline
\end{tabular}


Knowledge and Attitude of Women and Nurses regarding Pre-Conception Care: A Comparative Study

Table 2 shows that the age of the married women in the study sample ranged between 17 and 48 years, with about two-fifth having an intermediate level education (39.5\%). The majority of them were unemployed (85.1\%), living in rural areas (80.3\%), and having sufficient income (67.5\%).

Table2. Socio-demographic characteristics of women in the study sample $(n=750)$

\begin{tabular}{|c|c|c|}
\hline & Frequency & Percent \\
\hline Age: & & \\
\hline$<25$ & 221 & 29.5 \\
\hline $25-$ & 243 & 32.4 \\
\hline 30 & 158 & 21.1 \\
\hline $35+$ & 128 & 17.1 \\
\hline Range & \multicolumn{2}{|c|}{$17.0-48.0$} \\
\hline Mean \pm SD & \multicolumn{2}{|c|}{$28.1 \pm 5.7$} \\
\hline Median & \multicolumn{2}{|c|}{27.0} \\
\hline \multicolumn{3}{|l|}{ Education: } \\
\hline Illiterate & 138 & 18.4 \\
\hline Read/write & 121 & 16.1 \\
\hline Basic & 73 & 9.7 \\
\hline Intermediate & 296 & 39.5 \\
\hline University & 122 & 16.3 \\
\hline \multicolumn{3}{|l|}{ Job status: } \\
\hline Unemployed & 638 & 85.1 \\
\hline Working & 112 & 14.9 \\
\hline \multicolumn{3}{|l|}{ Residence: } \\
\hline Rural & 602 & 80.3 \\
\hline Urban & 148 & 19.7 \\
\hline \multicolumn{3}{|l|}{ Income: } \\
\hline Insufficient & 244 & 32.5 \\
\hline Sufficient & 506 & 67.5 \\
\hline
\end{tabular}

As presented in Table 3, most women in the study sample were gravida 2-4 (63.6\%), and para 2-4 (64.4\%), and more than one-fourth of them had previous abortions (28.5\%), while only $4.9 \%$ had previous pre-term labor. The majority of the women reported using contraception (78.7\%) and having an antenatal care in current pregnancy (86.8\%). Although around two-fifths of the women had previous pre-conception care (41.2\%) and counseling (43.1\%), a majority (70.1\%) were interested in pre-conception care. 
Knowledge and Attitude of Women and Nurses regarding Pre-Conception Care: A Comparative Study

Table3. Obstetric and medical history of women in the study sample ( $n=750)$

\begin{tabular}{|c|c|c|}
\hline & Frequency & Percent \\
\hline \multicolumn{3}{|l|}{ Gravidity: } \\
\hline 1 & 133 & 17.7 \\
\hline $2-4$ & 477 & 63.6 \\
\hline 5 & 140 & 18.7 \\
\hline \multicolumn{3}{|l|}{ Parity: } \\
\hline 1 & 173 & 23.1 \\
\hline $2-4$ & 483 & 64.4 \\
\hline 5 & 94 & 12.5 \\
\hline \multicolumn{3}{|l|}{ Abortions: } \\
\hline 0 & 536 & 71.5 \\
\hline $1+$ & 214 & 28.5 \\
\hline \multicolumn{3}{|l|}{ Preterm labor: } \\
\hline 0 & 713 & 95.1 \\
\hline $1+$ & 37 & 4.9 \\
\hline Had cesarean delivery & 410 & 54.7 \\
\hline Had previous labor complications & 431 & 57.5 \\
\hline Use contraception & 590 & 78.7 \\
\hline Plan pregnancy & 387 & 51.6 \\
\hline \multicolumn{3}{|l|}{ Current pregnancy: } \\
\hline Had antenatal care & 651 & 86.8 \\
\hline Had pregnancy complications & 349 & 46.5 \\
\hline Took medications & 580 & 77.3 \\
\hline \multicolumn{3}{|l|}{ Pre-conception care: } \\
\hline Had pre-conception care & 309 & 41.2 \\
\hline Had pre-conception counseling & 323 & 43.1 \\
\hline Interested in pre-conception care & 526 & 70.1 \\
\hline Have chronic diseases & 179 & 23.9 \\
\hline Had previous surgery & 207 & 27.6 \\
\hline
\end{tabular}

Table 4 points to generally low awareness of women about the elements of pre-conception care. This was prominent regarding the elements related to work hazards, chronic diseases, exercise, and vaccination, which were known by only less than one-third of them. Meanwhile, nurses' awareness was generally high, except for the elements of exercise and vaccination. The table demonstrates that the nurses' awareness was higher compared with women in all elements, with statistically significant differences $(\mathrm{p}<0.001)$. The only exceptions were related to the elements of talking to the doctor about pregnancy and having advice on medications, which were high in both groups. 
Knowledge and Attitude of Women and Nurses regarding Pre-Conception Care: A Comparative Study

Table4. Comparison of awareness of pre-conception care elements among nurses and women

\begin{tabular}{|c|c|c|c|c|c|c|}
\hline \multirow{3}{*}{ Pre-conception elements } & \multicolumn{4}{|c|}{ Group } & \multirow{3}{*}{$\mathrm{X}^{2}$ test } & \multirow{3}{*}{ p-value } \\
\hline & \multicolumn{2}{|c|}{ Women $(n=750)$} & \multicolumn{2}{|c|}{ Nurses $(n=106)$} & & \\
\hline & No. & $\%$ & No. & $\%$ & & \\
\hline Talking with doctor about pregnancy & 597 & 79.6 & 90 & 84.9 & 1.65 & 0.20 \\
\hline Medication advices & 558 & 74.4 & 84 & 79.2 & 1.16 & 0.28 \\
\hline Nutritional regimen & 480 & 64.0 & 84 & 79.2 & 9.60 & $0.002^{*}$ \\
\hline Vitamins/Folic acid & 419 & 55.9 & 84 & 79.2 & 20.95 & $<0.001^{*}$ \\
\hline Genital infections testing & 351 & 46.8 & 75 & 70.8 & 21.32 & $<0.001^{*}$ \\
\hline Family history & 289 & 38.5 & 76 & 71.7 & 41.77 & $<0.001^{*}$ \\
\hline Work hazards & 237 & 31.6 & 67 & 63.2 & 40.51 & $<0.001^{*}$ \\
\hline Chronic diseases & 206 & 27.5 & 73 & 68.9 & 72.46 & $<0.001^{*}$ \\
\hline Exercise & 203 & 27.1 & 62 & 58.5 & 42.91 & $<0.001^{*}$ \\
\hline Vaccination & 151 & 20.1 & 51 & 48.1 & 40.33 & $<0.001^{*}$ \\
\hline
\end{tabular}

(*) Statistically significant at $\mathrm{p}<0.05$

Table 5 indicates higher scores of knowledge of pre-conception care among nurses compared to women in the areas of chronic diseases (0.008), infectious diseases $(p<0.001)$, and service/elements $(p<0.001)$. Conversely, women knowledge scores were higher in vaccination $(\mathrm{p}=0.001)$. However, the total knowledge score was higher among nurses $(\mathrm{p}<0.001)$. Similarly, they had a higher total awareness score $(\mathrm{p}<0.001)$. As regards the attitude, only the attitude towards planning for pregnancy had a significantly higher score among nurses compared with women $(\mathrm{p}<0.001)$. Although the total attitude score tended to be higher among nurses, the difference did not reach statistical significance $(\mathrm{p}=0.08)$.

Table5. Comparison of scores of knowledge, awareness, and attitude towards pre-conception among nurses and women

\begin{tabular}{|c|c|c|c|c|c|c|}
\hline \multirow{3}{*}{ Scores of: } & \multicolumn{4}{|c|}{ Scores $(\max =100)$} & \multirow{3}{*}{$\begin{array}{c}\text { Mann } \\
\text { Whitney } \\
\text { Test }\end{array}$} & \multirow{3}{*}{ p-value } \\
\hline & \multicolumn{2}{|c|}{ Women $(n=750)$} & \multicolumn{2}{|c|}{ Nurses $(n=106)$} & & \\
\hline & Mean \pm SD & Median & Mean \pm SD & Median & & \\
\hline \multicolumn{7}{|l|}{ Knowledge: } \\
\hline Benefits & $70.5 \pm 34.5$ & 100.00 & $81.6 \pm 18.6$ & 88.90 & 1.13 & 0.29 \\
\hline Chronic diseases & $81.1 \pm 24.7$ & 100.00 & $86.5 \pm 25.5$ & 100.00 & 7.10 & $0.008^{*}$ \\
\hline Infectious diseases & $62.1 \pm 30.4$ & 66.70 & $75.0 \pm 36.7$ & 100.00 & 20.94 & $<0.001^{*}$ \\
\hline Nutrition & $47.6 \pm 23.3$ & 50.00 & $43.7 \pm 23.2$ & 33.30 & 1.73 & 0.19 \\
\hline Services/elements & $53.0 \pm 31.3$ & 66.70 & $65.7 \pm 23.2$ & 80.00 & 19.21 & $<0.001^{*}$ \\
\hline Risk factors & $69.0 \pm 22.9$ & 72.70 & $70.4 \pm 14.1$ & 72.70 & 1.19 & 0.27 \\
\hline Vaccination & $44.3 \pm 23.3$ & 33.30 & $35.2 \pm 31.5$ & 33.30 & 11.48 & $0.001^{*}$ \\
\hline Total knowledge & $61.6 \pm 13.0$ & 62.50 & $75.8 \pm 9.3$ & 77.80 & 105.11 & $<0.001^{*}$ \\
\hline Awareness of elements & $47.0 \pm 22.0$ & 40.0 & $70.4 \pm 30.1$ & 80.00 & 231.30 & $<0.001^{*}$ \\
\hline \multicolumn{7}{|l|}{ Attitude: } \\
\hline Pre-conception care & $73.2 \pm 24.3$ & 66.70 & $69.3 \pm 27.1$ & 66.70 & 1.45 & 0.23 \\
\hline Planning for pregnancy & $57.6 \pm 19.3$ & 58.30 & $67.2 \pm 17.2$ & 66.70 & 23.62 & $<0.001^{*}$ \\
\hline Pre-conception care services & $53.4 \pm 22.1$ & 50.00 & $55.2 \pm 24.2$ & 50.00 & 0.02 & 0.88 \\
\hline Total attitude & $60.4 \pm 13.6$ & 62.50 & $63.0 \pm 15.8$ & 64.70 & 3.07 & 0.08 \\
\hline
\end{tabular}

(*) Statistically significant at $\mathrm{p}<0.05$ 
Knowledge and Attitude of Women and Nurses regarding Pre-Conception Care: A Comparative Study

In multivariate analysis (Table 6), nurses' higher qualification, longer experience years, and provision of preconception care were identified as statistically significant independent positive predictors of their knowledge score, while their age and urban residence were negative predictors. The model explains $26 \%$ of the variation in the knowledge score. The table also illustrates that nurses' higher qualification and provision of pre-conception care were statistically significant independent positive predictors of their attitude score, whereas their urban residence was a negative predictor. The model also explains $26 \%$ of the variation in the attitude score.

Table6. Best fitting multiple linear regression model for nurses' knowledge and attitude scores

\begin{tabular}{|c|c|c|c|c|c|c|c|}
\hline & \multicolumn{2}{|c|}{$\begin{array}{l}\text { Unstandardized } \\
\text { Coefficients }\end{array}$} & \multirow{2}{*}{$\begin{array}{l}\text { Standardized } \\
\text { Coefficients }\end{array}$} & \multirow{2}{*}{ t-test } & \multirow{2}{*}{ p-value } & \multicolumn{2}{|c|}{$\begin{array}{l}\text { 95\% Confidence } \\
\text { Interval for B }\end{array}$} \\
\hline & B & $\begin{array}{l}\text { Std. } \\
\text { Error }\end{array}$ & & & & Lower & Upper \\
\hline \multicolumn{8}{|c|}{ Knowledge score } \\
\hline Constant & 89.29 & 6.62 & & 13.484 & $<0.001$ & 76.11 & 102.47 \\
\hline Age & -0.75 & 0.30 & -0.69 & 2.473 & 0.016 & -1.35 & -0.15 \\
\hline Qualification & 13.82 & 5.57 & 0.24 & 2.482 & 0.015 & 2.74 & 24.91 \\
\hline Experience & 0.78 & 0.30 & 0.70 & 2.544 & 0.013 & 0.17 & 1.38 \\
\hline Urban residence & -4.11 & 1.90 & -0.21 & 2.166 & 0.033 & -7.89 & -0.33 \\
\hline $\begin{array}{l}\text { Provides PC } \\
\text { service }\end{array}$ & 8.11 & 1.78 & 0.44 & 4.545 & $<0.001$ & 4.56 & 11.66 \\
\hline $\begin{array}{l}r \text {-square }=0.26 \\
\text { Variables entered }\end{array}$ & \multicolumn{7}{|c|}{$\begin{array}{l}\text { Model ANOVA: } F=6.91, p=0.001 \\
\text { courses, previous pre-conception ca }\end{array}$} \\
\hline \multicolumn{8}{|c|}{ Attitude score } \\
\hline Constant & 51.35 & 9.18 & & 5.597 & $<0.001$ & 33.09 & 69.61 \\
\hline Qualification & 30.85 & 10.06 & 0.30 & 3.067 & 0.003 & 10.84 & 50.87 \\
\hline Urban residence & -9.34 & 3.35 & -0.27 & 2.790 & 0.007 & -16.00 & -2.68 \\
\hline $\begin{array}{l}\text { Had previous PC } \\
\text { care }\end{array}$ & 9.39 & 3.05 & 0.29 & 3.075 & 0.003 & 3.31 & 15.47 \\
\hline $\begin{array}{l}r \text {-square }=0.26 \\
\text { Variables entered }\end{array}$ & \multicolumn{7}{|c|}{ Model ANOVA: $F=8.24, p<0.001$} \\
\hline
\end{tabular}

Concerning women's knowledge score, multivariate analysis in Table 7 demonstrates that their education level, previous pre-term labor, planning pregnancy, having antenatal care, having pre-conception care, and previous counseling were its statistically significant independent positive predictors. On the other hand, the history of labor complications and chronic diseases were negative predictors. The model explains $25 \%$ of the variation in the knowledge score. As regards women's attitude score, the table indicates that their urban residence, planning pregnancy, having antenatal care, having previous counseling, in addition to the knowledge score were its statistically significant independent positive predictors. Conversely, their education level was a negative predictor. The model explains $32 \%$ of the variation in the attitude score. 
Knowledge and Attitude of Women and Nurses regarding Pre-Conception Care: A Comparative Study

Table7. Best fitting multiple linear regression model for women's knowledge and attitude scores

\begin{tabular}{|c|c|c|c|c|c|c|c|}
\hline & \multicolumn{2}{|c|}{$\begin{array}{c}\text { Unstandardized } \\
\text { Coefficients }\end{array}$} & \multirow{2}{*}{$\begin{array}{l}\text { Standardized } \\
\text { Coefficients }\end{array}$} & \multirow{2}{*}{ t-test } & \multirow{2}{*}{$\mathrm{p}$-value } & \multicolumn{2}{|c|}{$\begin{array}{c}\text { 95\% Confidence } \\
\text { Interval for B }\end{array}$} \\
\hline & $\mathrm{B}$ & $\begin{array}{l}\text { Std. } \\
\text { Error }\end{array}$ & & & & Lower & Upper \\
\hline \multicolumn{8}{|c|}{ Knowledge score } \\
\hline Constant & 41.54 & 2.23 & & 18.638 & $<0.001$ & 37.17 & 45.92 \\
\hline Education & 0.95 & 0.32 & 0.10 & 2.968 & 0.003 & 0.32 & 1.58 \\
\hline Previous preterm & 3.52 & 1.53 & 0.07 & 2.299 & 0.022 & 0.51 & 6.52 \\
\hline Labor complications & -2.98 & 0.86 & -0.11 & 3.442 & 0.001 & -4.67 & -1.28 \\
\hline Plan pregnancy & 3.80 & 0.94 & 0.15 & 4.040 & $<0.001$ & 1.95 & 5.65 \\
\hline Has antenatal care & 3.17 & 1.34 & 0.08 & 2.367 & 0.018 & 0.54 & 5.79 \\
\hline Previous pre-conception care & 2.48 & 0.96 & 0.09 & 2.592 & 0.010 & 0.60 & 4.36 \\
\hline Previous counseling & 3.27 & 0.94 & 0.12 & 3.467 & 0.001 & 1.42 & 5.12 \\
\hline Chronic diseases & -2.14 & 1.03 & -0.07 & -2.076 & 0.038 & -4.16 & -0.12 \\
\hline \multicolumn{8}{|c|}{$\begin{array}{l}r \text {-square }=0.25 \quad \text { Model ANOVA: } F=26.56, p=0.001 \\
\text { Variables entered and excluded: age, residence, job, income, gravidity, abortions, pregnancy complications, }\end{array}$} \\
\hline \multicolumn{8}{|c|}{ Attitude score } \\
\hline Constant & 28.08 & 2.42 & & 11.607 & $<0.001$ & 23.33 & 32.83 \\
\hline Education & -0.84 & 0.31 & -0.09 & 2.684 & 0.007 & -1.46 & -0.23 \\
\hline Urban residence & 2.29 & 1.03 & 0.07 & 2.223 & 0.027 & 0.27 & 4.32 \\
\hline Plan pregnancy & 6.59 & 0.90 & 0.24 & 7.305 & $<0.001$ & 4.82 & 8.37 \\
\hline Previous counseling & 2.80 & 0.88 & 0.10 & 3.171 & 0.002 & 1.07 & 4.53 \\
\hline Knowledge score & 0.34 & 0.04 & 0.33 & 9.652 & $<0.001$ & 0.27 & 0.41 \\
\hline
\end{tabular}

\section{DISCUSSION}

The results of the present study indicate that the knowledge of pre-conception care and the awareness of its elements is discrepant between nurses and married women, with these latter having lower scores of both. Meanwhile, the attitudes seem to be ambivalent with no overall significant difference between women and nurses.

According to the present study findings, the majority of the nurses and women considered talking to the doctor about pregnancy and having advice on medications as the main elements of pre-conception care. This reflects a common misconception about this service since the pre-conception care is not just the physician's role, but it encompasses other areas and other specialties, particularly nursing and midwifery.

Conversely, the awareness of vaccination as an essential element of pre-conception care was found to be low among both the nurses and the women in the current study. It came at the bottom rank of awareness among the two groups. The finding is worrisome since it overlooks the role of vaccination before pregnancy, and limits 
its role only to the vaccines provided to women during their pregnancy. A similarly low level of awareness of vaccination before conception was revealed by Ordinioha $\&$ Brisibe in Nigeria [24]. Thus, even in developed countries such as the United States, the vaccination coverage rate of Tetanus, diphtheria and acellular pertussis is low among pregnant women [25].

Similarly, the awareness of the nurses and women in the present study about exercise as an important element of pre-conception care was low. This was particularly evident among women. This reflects a generally deficient societal look at physical activity as a part of a healthy lifestyle that affects health in general, and pregnancy and its outcomes in particular. In line with this, Ribeiro and Milanez, in Brazil, found that only approximately onefifth of the studied women engaged in an adequate exercise, defined as at least three times per week. The lack of adequate exercising was attributed to lack of time and feeling of tiredness [26].

The present study has also revealed that women's awareness about work hazards and chronic diseases as elements of pre-conception care was low and significantly lower compared with the nurses. The low awareness of the work hazards night is attributed to that the great majority of these women are housewives and unemployed. Meanwhile, their low awareness of the importance of chronic diseases that may affect pregnancy, and their importance as a pre-conception care element could be attributed to the low prevalence of chronic diseases in this group of women given their mostly young age. The findings are in congruence with those of Zhou et $\boldsymbol{a l}$ in China, and Teng \& Ahmed in Canada were a majority of the respondent women had low awareness of preconception care [27-28].

Concerning the knowledge of pre-conception care, the current study findings revealed generally acceptable scores for both women, median scores exceeding $62 \%$, and nurses, median scores exceeding $77 \%$. For both, the scores of knowledge were high regarding the benefits of pre-conception care. Nonetheless, a striking finding was that women' knowledge of vaccination in pre-conception care was significantly higher compared with nurses' knowledge. This is an alarming result that necessitates urgent interventions to improve nurses' related knowledge. In agreement with this, (Bayrami et al) reported that midwives' knowledge of preconception care was moderate [29]. Moreover, a study in Brazil demonstrated that the knowledge of the healthcare providers about pre-conception care, particularly regarding nutrition and folic acid supplementation was low [30].

Meanwhile, our results concerning women's knowledge are midway among similar studies in the literature. They are higher compared with studies from Iran [31], Nigeria [19], Sudan [20], and Nepal [32]. However, they are lower compared with studies from Egypt [33], Jordan [34], and Saudi Arabia [35]. The discrepancies are certainly attributed to differences in the study settings and the characteristics of the studied samples.

As regards the factors influencing nurses' knowledge of pre-conception care, the present study results showed that a higher nursing qualification, more experience years, and the provision of pre-conception care at the center were associated with better knowledge score. These factors are expected to enhance nurses' knowledge, especially the factor of the provision of pre-conception care at the center, which may force the nurse to acquire needed knowledge to be able to provide this service. The negative association between age and knowledge score is quite known given the decreasing ability and eagerness to learn with advancing age. Thus, unmet educational needs regarding pre-marital and pre-conception care have been elucidated in a study on Iranian midwives [36]. Meanwhile, our finding of the positive influence of nurses' experience years on their knowledge of preconception care is in agreement with the results of Tokunbo et al study in Nigeria [37].

For women, the factors positively affecting their knowledge scores were their educational level, having previous pre-term labor, planning pregnancy, having antenatal care, having pre-conception care, and previous counseling. The effects of these factors are quite plausible given the influence of education on knowledge, as well as the positive effect of the actual utilization of pre-conception care. As for the positive association between previous pre-term delivery and knowledge, it could be explained by the worries of the woman having such incident, which 
may push her to acquire more knowledge about pre-conception care. In congruence with this, Dunlop et al demonstrated a significant positive association between women's educational attainment and their knowledge of pre-conception care knowledge [38]. On the same line, previous studies showed that women's knowledge of preconception care was significantly influenced by their educational status, obstetric history, income, and family planning [39-41].

The present study has also assessed the attitude towards pre-conception care. The only significant difference between nurses and women was regarding the attitude towards planning for pregnancy, which was higher among nurses. In line with this, a study in the United Kingdom found that a great majority of the nurses under study had a positive attitude towards preconception care, and were convinced with its beneficial effects on maternal and neonatal outcomes [37].

Nonetheless, the median attitude scores of both groups in the present study were around $60 \%$, reflecting more uncertainty or ambivalence. This could be related to the related levels of knowledge and awareness of the elements of pre-conception care. A more positive attitude towards pre-conception care and related healthy lifestyles was revealed among women in a study in the United States [42], which might be attributed to their higher socioeconomic level compared to our sample. Similarly, although women in underprivileged areas in the United Kingdom had a deficient knowledge of preconception care, their related attitudes tended to be positive [43].

The factors positively affecting nurses' attitude scores were their higher qualification and their provision of pre-conception care. These are similar to the factors affecting their knowledge and the same explanations might apply. Meanwhile, the nurses' urban residence turned to be a negative predictor of their attitude score. This might be due to that the nurse not living in the same community might be less able to share the same prevalent attitudes and conceptions.

As for women's attitude score, the factors having a positive influence turned to be their urban residence, planning pregnancy, having antenatal care, and having previous counseling. These factors reflect a high level of health awareness and behavior, which would certainly positively shape women's attitude. Moreover, a higher knowledge score was associated with more positive attitude score, thus indicating the importance of improving women's knowledge of pre-conception care. In this respect, van der Zee et al in the Netherlands reported that was reluctant to have preconception care despite their related positive attitude, and this was attributed to their lack of knowledge about the true concept of preconception care [44].

\section{CONCLUSION AND RECOMMENDATIONS}

The conclusion is that nurses' knowledge of pre-conception care and their awareness of its elements is better compared to married women, although not very high in both. They have generally hesitant attitudes with no significant overall difference. The study indicates the need for the urgent establishment of a formal preconception care in PHC and MCH centers, along with training programs for nurses in the provision of its services. The program needs to be promulgated in the community served by these centers, as well as in media.

\section{REFERENCES}

1. Temel S., van Voorst S.F., and de Jong-Potjer L.C. (2015): The Dutch national summit on preconception care: a summary of definitions, evidence and recommendations. J Community Genet.; 6:107-115. [Crossref], [PubMed] [Google Scholar]

2. Dean S., Lassi Z., Imam A., and Bhutta Z. (2014): Pre-conception care: promoting reproductive planning. Reproductive Health; 11(Suppl 3): S2.

3. Zühlke L. and Acquah L. (2016): Pre-conception counselling for key cardiovascular conditions in Africa: optimising pregnancy outcomes. Cardiovasc J Afr;;27(2):79-83. doi: 10.5830/CVJA-2016-017. 
4. Wilson R.D. (2017): Choosing Pre-Conception Planning for Women/Families: Counselling and Informed Consent (Part 2) - Pre-Conception Reproductive Planning, Lifestyle, Immunization, and Psychosocial Issues. J Obstet Gynaecol Can. pii: S1701-2163(17)30721-1. doi: 10.1016/j.jogc.2017.08.037.

5. Ali M., Elshabory N., Hassan H., Zahra N., Alrefai H. (2018): Perception About Premarital Screening and Genetic Counseling Among Males and Females Nursing Students. IOSR Journal of Nursing and Health Science (IOSR-JNHS); 7(1): 51-57.

6. Gregg A.R. (2017): Futuristic Look at Genetic and Birth Defect Diagnoses and Treatments. Clin Obstet Gynecol.;60(4):867-877. doi: 10.1097/GRF.0000000000000327.

7. World Health Organization [WHO], (2016): Global action plan for the prevention and control of no communicable disease 2013- 2020. C2013. Available from: http://apps.who.int/iris/ bitstream/10665/94384/1/ 9789241506236_eng.pdf [cited 2016 Jul 6].

8. Steel A., Lucke J., and Adams J. (2015): The preva-lence and nature of the use of preconception services by women with chronic health con-ditions: an integrative review. BMC Women's Health; 15(1): 14.

9. Kost K. (2015): Unintended pregnancy rates at the state level: Estimates for 2010 and trendssince 2002. Retrieved from https://www. guttmacher.org/fact-sheet/unintendedpregnancy-United-states.

10. Bye A., Shawe J., Stephenson J., Bick D., Brima N., and Micali N. (2016): Differences in pre-conception and pregnancy healthy lifestyle advice by maternal BMI: Findings from a cross sectional survey. Midwifery.; 42:38-45. doi: 10.1016/j.midw.2016.09.013. Epub 2016 Sep 23.

11. Bianca I., Geraci G., Gulizia M.M., Egidy Assenza G., Barone C., Campisi M., Alaimo A., Consensus Document of the Italian Association of Hospital Cardiologists (ANMCO), Italian Society of Pediatric Cardiology (SICP), and Italian Society of Gynaecologists and Obstetrics (SIGO) (2017): pregnancy and congenital heart diseases. Eur Heart J Suppl.;19 (Suppl D): D256-D292. doi: 10.1093/eurheartj/sux032.

12. Hassan H., Zahran K., Youness E., Nady F. (2015): Pregnant Women's Awareness, Intention and Compliance regarding Folic Acid Usage for Prevention of Neural Tube Defects According to Health Belief Model in BeniSuef City. Pyrex Journal of Nursing and Midwifery; 1(3): 13-26.

13. James T. (2015): Preconception/inter-conception care- training curriculum. Illions department of human services.

14. Habib M.A., Raynes-Greenow C., Nausheen S., Soofi S.B., Sajid M., Bhutta Z.A., and Black K.I. (2017): Prevalence and determinants of unintended pregnancies amongst women attending antenatal clinics in Pakistan. BMC Pregnancy Childbirth.;17(1):156. doi: 10.1186/s12884-017-1339-z.

15. Slater C., Morris L., Ellison J., and Syed A.A. (2017): Nutrition in Pregnancy Following Bariatric Surgery. Nutrients.;9(12). pii: E1338. doi: 10.3390 /nu9121338.

16. Hassan H., Nady F., Youns E., Zahran K. (2016): Call for Change Level of Knowledge, Awareness and Attitude to Follow a High Folate Diet Among Pregnant Women. IOSR Journal of Nursing and Health Science; 5(1): 93-100. doi: 10.9790/1959-051293100

17. Patabendige M. and Goonewardene I.M. (2013): Preconception care received by women attending antenatal clinics at a Teaching Hospital in Southern Sri Lanka. SriLanka J Obstet Gynaecol.; 35(1).

18. Idris S.H., Sambo M.N., and Ibrahim M.S. (2013): barriers to utilization of maternal health service in a semi urban community in Norther Nigeria. Niger Med J.; 54(1):6.

19. Olayinka 0.A. (2014): Awareness and barriers to utilization of maternal health care services among reproductive women in Amassoma community, Bayelsa State. Int J Nurs Midwifery.; 6(1):6. 
20. Ahmed K., Elbashir I., Mohamed S., Saeed A., Alawad A. (2015): Knowledge, attitude and practice of preconception care among Sudanese women in reproductive age about rheumatic heart disease at Alshaab and Ahmad Gassim hospitals 2014-2015 in Sudan. Basic Research Journal of Medicine and Clinical Sciences; 4(7):199-203.

21. Van der Heijde C.M., Collard P.R., Vonk P., and Meijman F.J. (2018): Better informed is better decided: Addressing the risks of delaying childbearing for female higher educational students. Int J Adolesc Med Health. pii: /j/ijamh.ahead-of-print/ijamh-2017-0175/ijamh-2017-0175.xml. doi: 10.1515/ijamh-20170175. [Epub ahead of print]

22. Wang Y., Zhou H., Zhang L., Zhong Q., Wang Q., and Shen H. (2017): Prevalence of chronic hepatitis B and status of HBV care among rural women who planned to conceive in China. Sci Rep.;7(1):12090. doi: 10.1038/s41598-017-12005-2.

23. Dunlop A.L., Logue K.M., Thorne C., and Badal H.J. (2013a): Change in women's knowledge of general and personal preconception health risks following targeted brief counseling in publicly funded primary care settings. American Journal of Health Promotion.; 27(sp3): S50-S7. https://doi.org/10.42 78/ajhp.120116QUAN-39.

24. Ordinioha B. and Brisibe S. (2015): Alcohol consumption among pregnant women attending the ante. natal clinic of a tertiary hospital in South. South Nigeria. Nigerian Journal of Clinical Practice; 18(1): 13- 17.

25. Healy C.M., Ng N., Taylor R.S., Rench M.A., and Swaim L.S. (2015): Tetanus and diphtheria toxoids and acellular pertussis vaccine uptake during pregnancy in a metropolitan tertiary care center. Vaccine.;33(38):4983-7. doi: 10.1016/j.vaccine.2015.07.018. Epub 2015 Jul 17.

26. Ribeiro C.P. and Milanez H. (2011): Knowledge, attitude and practice of women in Campinas, São Paulo, Brazil with respect to physical exercise in pregnancy: a descriptive study. Reprod Health.; 8(1):31. https:// doi. org/10.1186/1742-4755-8-31.

27. Zhou Y., Lv J., Bai G., Zhao R., Liu R., Yan Y., Chen L., Zhang Y., Luo X., and Hao M. (2010): "Study on connotation and status quo of preconception care". Chinese Health Resources; 13(4): 162-4.

28. Teng J. and Ahmed R. (2017): "Examining preconception care-related knowledge and attitudes among Chinese immigrants in Canada", International Journal of Migration, Health and Social Care;13 (Issue: 1):p.69-92, https://doi.org/10.1108/IJMHSC-10-2015-0039

29. Bayrami R., Ebrahimipour H., Ebrahimi M., Forootani M., and Najafzadeh B. (2013): Health care provider s' knowledge, attitude and practice regarding pre-conception care. J Res Health; 3(4):519-26.

30. Ferreira F.R., Russo Akiba H.R., Araujo Júnior E., Figueiredo E.N., Abrahão A.R. (2015): Prevention of birth defects in the pre-conception period: knowledge and practice of health care professionals (nurses and doctors) in a city of Southern Brazil. Iran J Reprod Med.;13(10):657-64.

31. Ghaffari F. (2013): Application of Donabedian Quality-of-Care Framework to Assess the Outcomes of Preconception Care in Urban Health Centers, Mashhad, Iran in 2012. J Midwifery Reprod Health; 2(1):50-9.

32. Gautan P. and Dhakal R. (2016): Knowledge on preconception care among reproductive age women. Saudi J Med Pharm Sci.; 2(1):6.

33. Mohammed A.R., Mohammed S.A., and Abdulfatah A.M. (2013): Congenital Anomalies among Children: Knowledge and Attitude of Egyptian and Saudi Mothers. Biol Agric Healthcare.; 3:2224-3208. 
34. Al-Akour N.A. (2015): Awareness of preconception care among women and men: a study from Jordan. J Obstet Gynaecol.; 35:5.

35. Madanat A.Y. and Sheshah E. (2016): Preconception care in Saudi women with diabetes mellitus. J Fam Community Med.; 23(2):6.

36. Abedian K., Charati J.Y., Samadaee K., and Shahhosseini Z. (2014): A Cross-sectional Study of Midwives' Perspectives Towards their Professional Educational Needs. Mater Sociomed.;26(3):182-5. doi: 10.5455/ msm.2014.26.182-185. Epub 2014 Jun 21.

37. Tokunbo O.A., Abimbola O.K., Polite I.O., and Gbemiga O.A. (2016): Awareness and perception of preconception care among health workers in Ahmadu Bello University Teaching University, Zaria. Trop J Obstet Gynaecol; 33: 149-52.

38. Dunlop A.L., Dretler A.W., Badal H.J., and Logue K.M. (2013b): Acceptability and potential impact of brief preconception health risk assessment and counseling in the WIC setting. American Journal of Health Promotion; 27(sp3): S58-S65.

39. World Health Organization [WHO], (2013): Preconception health. Regional expert group consultation on preconception care, in newdelhi. India: World Health Organization; 2013.

40. Masoumeh P. (2015): Knowledge of pregnant women about congenital anomalies: A cross-sectional study in north of Iran. Indian J Health Sci.;8(1):41.

41. Ayalew Y., Mulat A., Dile M., and Simegn A. (2017): Women's knowledge and associated factors in preconception care in adet, west gojjam, northwest Ethiopia: a community based cross sectional study. Reproductive Health.;14:15. doi:10.1186/s12978-017-0279-4.

42. Funk K.L., LeBlanc E.S., Vesco K.K., and Stevens V.J. (2015): Women's attitudes towards a pre-conception healthy lifestyle programme. Clin Obes.;5(2):67-71. doi: 10.1111/cob.12088.

43. Tuomainen H., Cross-Bardell L., and Bhoday M. (2013): Opportunities and challenges for enhancing preconception health in primary care: qualitative study with women from ethnically diverse communities. BMJ Open ;3: e002977.

44. Van der Zee B., de Beaufort I.D., Steegers E.A., and Denktaş S. (2013): Perceptions of Preconception Counselling Among Women Planning a Pregnancy: A Qualitative Study. Family Practice; 30(3): 341-346.

Citation: Ekbal Abd El Rheem Emam, Amany Hassan Abd El Rheem, Naglaa Mohammed Amein Ghanem, Hanan Elzeblawy Hassan, "Knowledge and Attitude of Women and Nurses regarding Pre-Conception Care: A Comparative Study". American Research Journal of Nursing. 2019; 5(1): 1-15.

Copyright (c) 2019 Ekbal Abd El Rheem Emam, Amany Hassan Abd El Rheem, Naglaa Mohammed Amein Ghanem, Hanan Elzeblawy Hassan, This is an open access article distributed under the Creative Commons Attribution License, which permits unrestricted use, distribution, and reproduction in any medium, provided the original work is properly cited. 